Article

\title{
Three Dimensions of Design for Sustainable Behaviour
}

\author{
Hyunjae Daniel Shin *(i) and Richard Bull
}

School of Architecture Design and Built Environment, Nottingham Trent University, Nottingham NG1 4FQ, UK

* Correspondence: daniel.shin@ntu.ac.uk

Received: 4 August 2019; Accepted: 21 August 2019; Published: 24 August 2019

check for updates

\begin{abstract}
Designing products to be more sustainable is crucial if the UK is to meet the challenge of its ambitious new carbon reductions targets by 2050. How designers, manufacturers and service providers conceptualise behaviour is key to understanding how there will be widespread adoption of new products. The research area referred to as Design for Sustainable Behaviour has emerged to explore measures of reducing environmental impact through moderating the way people use products, services and systems. To date, though, characterisations of its strategies have been relatively one-dimensional, with an emphasis on environmental psychological approaches to understanding behaviour. This paper draws on a wider set of literature and academic disciplines to propose a conceptual framework that incorporates three dimensions: empowerment, information and motivation. This three-dimensional framework argues for a wider understanding of behaviour that encompasses feedback, participation and acknowledgement of the wider social and organisational context that behaviour is situated in. This framework is presented, the implications for theory and practice are explored, and a challenge is laid down to designers, academics and policymakers to consider how this framework can be applied, tested and further developed.
\end{abstract}

Keywords: design for sustainable behaviour; decision making; feedback; feedforward; participation; motivation; internalisation

\section{Introduction}

Designing products to be more sustainable is crucial if the UK is to meet its challenging new aspiration of reducing carbon emissions to net zero by 2050. Raworth [1] reminds us in 'Doughnut Economics' that modern life, underpinned by a capitalist consumption based worldview and practice, is energy intensive, resource inefficient and unequal in its distribution of wealth. Significant benefits have been noted by the Waste and Resources Action Programme (WRAP), who have estimated that businesses in the UK might save $£ 23$ billion per year from a circular economy approach. For example, $30 \mathrm{Mt}$ less material input into the economy by 2020, 20\% less waste produced (50 Mt less waste) and $20 \mathrm{Mt}$ more materials recycled back into the economy [2]. The WRAP notes four key ways of realising these savings which place design for sustainable behaviour at the heart:

(1). Adopting lean production methodologies (i.e., making goods with a lower material requirement);

(2). Less waste in manufacture and business;

(3). Decreasing the amount of working products currently being disposed;

(4). Shifting to a 'services' approach (i.e., increasing the amount of products that are leased).

How designers, manufacturers and service providers conceptualise behaviour is key to understanding how there will be widespread adoption of new products. Whilst current EU legislation, notably the Energy Efficiency Directive, is driving more efficient products, there is obvious uncertainty as to how this will play out long term. User behaviour and market led solutions will be vital, as can be seen by the increasing demand for less single use plastic. This conceptual paper addresses 
this debate by exploring the dimensions considered by designers when conceptualising influences on user behaviour. However, user behaviour is typically conceptualised through one dimension: power in decision making underpinned by limited understandings of behaviour. We propose a new conceptual framework that extends its notion by integrating a wider understanding of behaviour, incorporating three dimensions; empowerment, information and motivation. The theoretical and practical implications of this framework are discussed, and the presented typology can practically support related practices within Design for Sustainable Behaviour (DfSB) to better help the strategy selection and to instigate the internalisation of behavioural change in a more effective way.

\section{Background-Dimension of Power in Decision Making}

Design for Sustainable Behaviour (DfSB) has emerged under the domain of sustainable design, which explores the measures of reducing environmental impact through moderating the way people use products, services and systems [3]. In the past years, scholars in this field have proposed various different design strategies and dimensions to consider during the process of designing such products or systems [4]. Earlier studies have focused on identifying design strategies to bring about a behavioural change for achieving environmental benefit [5-8]. More recently, a number of empirical data are being reported that evaluated the acceptance and effectiveness of these strategies through case studies [9-11] that were focussed on strategy selection for targeted behaviour [12-14]. Further theoretical development has been made to improve its design methodologies, processes and toolbox, incorporating behavioural psychology and the consideration of ethical implications [15-19]. While studies on DfSB continue to grow, concerns are being raised that limitations of these DfSB strategies are rarely discussed [20]. These limitations would encompass issues such as a risk of not achieving an intended behaviour, obsolescence of an intervention and insufficient data from a longitudinal study to evaluate the effectiveness of DfSB strategies. The question still remains whether those changed behaviours induced by design-led interventions would continue over a prolonged period. More specifically, how can design help increase the effectiveness of the strategy and how can intended behaviour be reproduced, maintained and internalised?

A categorisation has been suggested through an extensive literature review around the works of DfSB, as previously summarised [21], and practical guidance for design practitioners has been developed and assessed [22]. While its theoretical foundations have been greatly advanced, the lack of a unified framework in exploring its strategies has been raised as a central concern $[13,18]$. Kuijer and Bakker [17] have rightly challenged DfSB to adopt a wider understanding of behaviour, which incorporates knowledge around social practices in order to gain a deeper understanding of sustainable consumption. Furthermore, it has been pointed out that discussions are limited in relation to how strategies can be applied according to their target group or in-situ, and more empirical understanding is needed to identify dimensions that account for their effectiveness [23].

Coskun, Zimmerman and Erbug [21] suggest that assessment of effectiveness would require a series of longitudinal studies and also an improvement of the dimensions discussed in the literature to help strategy selection. However, it has been suggested and evidenced that the combination of intervention is much more effective when applying the sum of the two to promote pro-environmental behaviour [24]. So far, DfSB approaches are interpreted one-dimensionally on a horizontal axis of 'power in decision making' (see Figure 1).

In any behavioural change context, building a habitual behaviour, i.e., internalising the changed behaviour without the need of intervention, would be an ideal transition. Hence, gaining a better understanding of the relationship between dimensions of DfSB and considering this behavioural transition is necessary for improving strategies that bring profound and lasting impact on people's behaviour. Considering the notion of complexity involved in daily practice, and if DfSB involves the intention of breaking the habit of people, dimensions should reflect the complex nature of human behaviour. 
This paper therefore discusses and proposes a framework that suggests three dimensions to consider when designing design-led intervention to induce sustainable behaviour. The three dimensions comprise of empowerment, information and motivation. Each dimension in the framework is carefully constructed and informed by an integrative review in the field of DfSB, behavioural science and theories from social psychology.

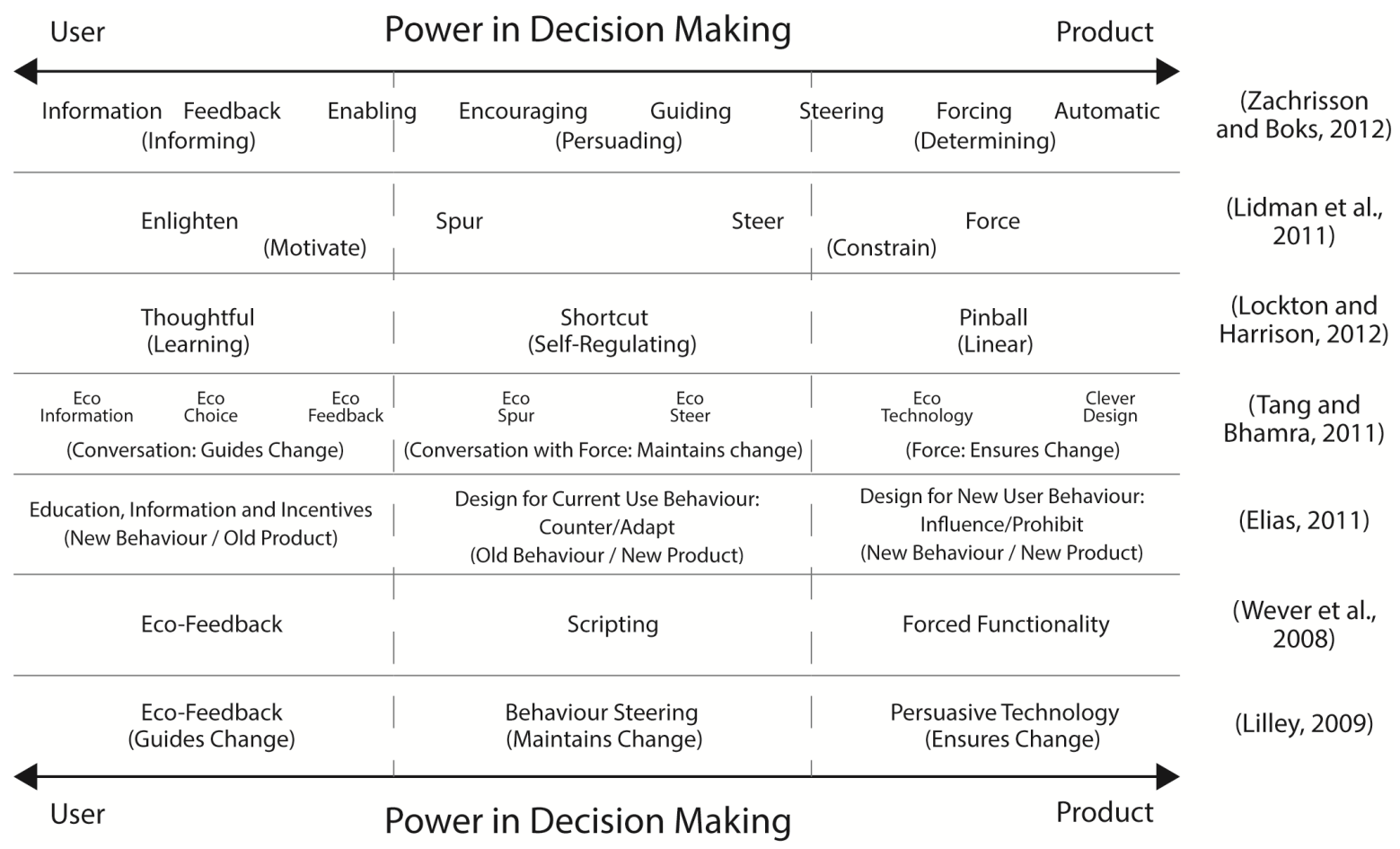

Figure 1. Dimension of 'power in decision making' [18].

\section{Three Dimensions}

\subsection{Power in Decision Making}

One of the early suggested design strategies for inducing an intended behaviour is the 'script' approach defined as "a product layout guiding the behaviours of the user, in a more or less forceful way" [25] (p. 120). The idea is to stimulate users to perform intended behaviours through "value, incentive and rules"; that are scripted in between the service and the product. However, this approach can conversely constrain behaviours through design attributes similar to what Norman [26] describes as 'affordances' and 'constraints'; the appearance of the device providing clues to its operation. Norman later details the distinction between 'perceived affordance' and 'real affordance'. He argues that affordances can guide certain behaviours through 'real' physical objects, without people having to think about their own actions, whereas the 'perceived affordance' is a scripted design application that allows users to perceive the 'possibility' of a certain action.

One of the earliest frameworks within DfSB studies was first proposed by Lilley et al. [27], which was later detailed into seven strategies by Bhamra et al. [28] using the dimension of 'power in decision making', or was referred to as the 'axis of influence' [29]. Later studies attempted to categorise strategies within this dimension by comparing the terminologies, as shown in Figure 1 $[18,30]$. The spectrum of this dimension mainly differentiates strategies by the distribution of control between the user and the product. One end of the spectrum uses a script to induce a behavioural change whereby power in decision making relies more on the user in action. The other end, product or artefact uses exerted force to ensure a behavioural change, avoid unintended behaviour or to ensure a change without changing behaviour, not necessarily involving a conscious decision by the user. In this case, 
users will be unaware of any values, incentives or rules instigated by the intervention. Gardner and Stern [31] categorise this strategy as 'efficiency behaviour', where adoption of these products will generate certain incentives without interfering with people's behaviour. These strategies often involve intelligent products that may have a greater impact but fail to account for ethical considerations. This is similar to what Latour [32] refers to as the 'delegation to machines'; and Norman calls 'real affordance' [26], where they argue that undermining forces on behavioural change can be eliminated by complete delegation of all actions to the device in question; also known as 'black-boxed script' [33]. However, given the urgency of the environmental problem, Lilley, Lofthouse and Bhamra [27] argue that these interventions can be necessary and provide a starting path of action, which could potentially reduce the intended impact. Nevertheless, human actions are not as predictable as a machine's; therefore, designed inscription for inducing new behaviour may also be resisted by users who are social agents [34].

\section{Empowerment}

Intelligent products and new technological interventions have been causing moral and ethical concerns among scholars over the notion of them having a lack of 'autonomous' control. Jelsma [35] states that designers are the people who inscribe 'morality' in the thing they make and that immorality (e.g., over-consumption of energy) has to be corrected by moral behaviour. Brey $[36,37]$ has argued that autonomy of the user may be hindered when their essential everyday actions are 'trained' by behaviour steering technologies. To some degree, these technologies set goals and plans on behalf of users, whereby humans no longer become an autonomous decision maker. This type of 'automated' strategy is referred to as being 'sustainable by stealth' [27]. Tang [38] has discussed these concerns and pointed out their weaknesses in; lack of normative and motivational change, rebound effect, low user acceptance and ethical/moral issues over being 'stealthy'. However, when 'power in decision making' is with the user, the motivational change and user acceptance become greater [38].

It is argued that changed behaviour can be maintained through repeated exposure to similar interventions [39]. In addition, the effectiveness of interventions depends on the process of changing existing habits, initiating new behaviour, and the maintenance of that behaviour $[40,41]$. However, De Young [42] argues that interventions should focus on maintaining the steadiness of changed behaviour, and at the same time minimise the need for repeated interventions. In increasing the effectiveness of DfSB strategy, it was suggested that when the 'power in decision making' is delegated to a user, the normative and motivational change will increase, which in turn leads to greater user acceptance of implemented intervention [38]. Whilst many scholars emphasise the need for longitudinal study for DfSB strategies, it is critical to account for how a design element should help increase effectiveness and how intended behaviour can be reproduced, maintained and internalised in the longer-term with greater autonomy to reinforce their motivation. In other words, enabling the user to build a strong sense of empowerment and take responsibility for their volition and choices towards practicing sustainable behaviour.

An increasingly popular model for conceptualising empowerment is Shelly Arnstein's Ladder of Participation [43] (see Figure 2). In her model, Arnstein argues that citizen involvement is a fairer way of distributing power in our society, especially within the planning context. At the bottom of the ladder are one-dimensional forms of communication that act as a substitute for more authentic types of interaction. Arnstein believes that 'citizen control' should be at the top of the ladder, thus signifying a redistribution of power to those who are often excluded from the decision making processes within society [43]. This model has been successfully applied to a range of disciplines, most recently energy behaviours in buildings and organisations [44]. 


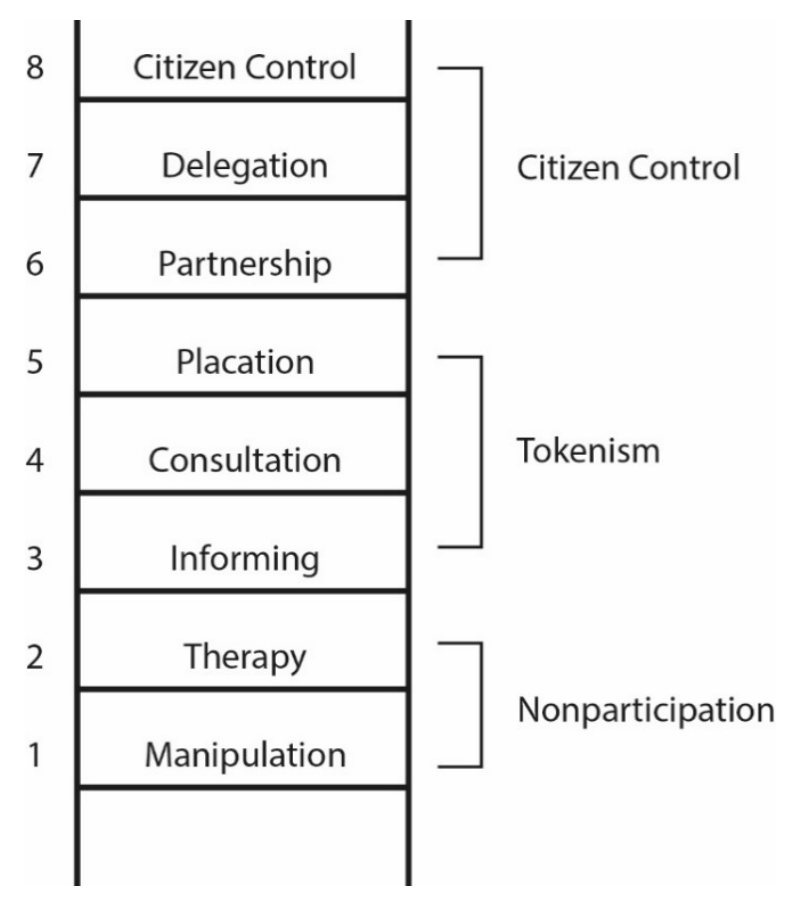

Figure 2. Arnstein's Ladder of Participation [43].

\subsection{Information (Feedback)}

The need to move beyond information-provision and explore innovative ways of providing feedback is central to behaviour change. One of the most conventional strategies in behavioural change is the 'carrot and stick' approach, which originates from behavioural psychology that 'we learn what to do (and what not to do) by experiencing positive (and negative) reinforcements (rewards or penalties) for our behaviour' [45] (p.109). The second most discussed dimension is the function of 'feedback' within DfSB studies. A user agentive performance indicator such as a smart-meter or eco-feedback has proven to bring a positive impact on household energy consumption [46]. This kind of system, in theory, may be recognised as an applicable method in increasing the awareness of one's behaviour [47], especially when the electricity consumption is linked to appliances and associated activities. However, the effectiveness of these systems is still in debate $[48,49]$. Some criticisms were presented against eco-feedback systems, stating that they have a similar strategy to an educational intervention where information itself does not necessarily lead to behaviour change [50]. According to Strengers [51], eco-feedback is likely to appeal only to those who are environmentally motivated, and conservation benefits may languish over a period of time. Studies suggest that many householders discontinued using the energy feedback system, or the anticipated behavioural change was absent due to the disconnection between consumption data and the perceived non-negotiability (e.g., using a hairdryer every morning) of everyday practices [48,51,52]. This emphasises the fact that the feedback device only provides information about how much people consume, rather than linking the behaviour consequences to generate a spontaneous occurrence for internalisation (i.e., goal-setting). Therefore, it is more important for feedback interventions to reinforce self-efficacy [53] to sustain the intended behaviour at later stages. Overall, whilst research has shown that feedback can impact on changing user behaviour, saving between $5 \%-15 \%$ on average [46], there is certainly no obvious cause and effect between installing more innovative domestic energy metering that would lead to householders changing their behaviour. More often than not, research has shown that these devices fade into 'the background' [54].

These factors may relate strongly to how the frequency of feedback is delivered. It has been seen that eco-feedback can have an impact on energy saving, with recent studies focusing on gathering empirical evidence to measure the effectiveness of different types of feedback delivery [55]. Yun, Aziz 
and Lasternas [55] investigated the implications of energy feedback design presentations (e.g., visuals, time range and time intervals) and suggested that people often get confused about metaphoric information (e.g., $\mathrm{CO}_{2}$ and Tree), but longer-term (weekly) usage information was more useful and was preferred by the study participants. In the past, Abrahamse et al. [56] suggested that the more frequently the feedback information was given to users, the effectiveness measured was much higher. Hence, more variables, such as types of information, presentation of visuals and frequency of feedback, should carefully be considered when constructing the strategies within the spectrum of the 'Information' dimension; but also the way in which feedback aspects are associated with other dimensions should be accounted for. For example, research into energy behaviour change strategies in organisations has shown that behaviour can be heavily influenced by social, organisational and cultural factors [44].

It has been suggested that the combination of influences of attitude and contextual factors, such as incentives or penalties, is much more effective at bringing about pro-environmental behaviour [24]. Whilst many studies have positioned the use of a 'feedback' feature as being a particular characteristic within the dimension of 'power in decision making', Backlund et al. [57] proposed a two-axis matrix, where one axis represents a spectrum of frequency of feedback ranging from slow to instant; and the other axis represents user behaviour mode ranging between active and passive, as being similar to the notion of distributing control within the dimension of 'empowerment' (see Figure 3). Rather than having a single axis (dimension) to categorise the types of strategies, two-axis can provide better typology for strategy selection, e.g., a strategy that has slow feedback but allows the user to be more active about decision making and behaviour.

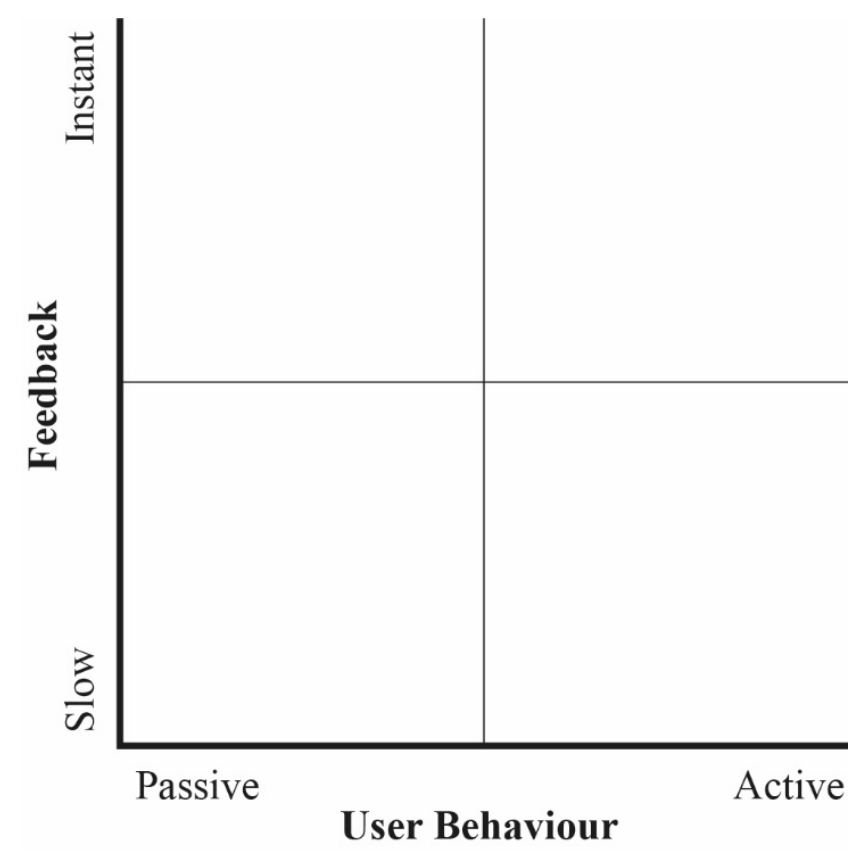

Figure 3. Two-axis design intervention matrix [57].

Feedback and Forward

According to Van Houwelingen and Van Raaij [58], there are several functions of feedback. First, the feedback has a process where consumers learn the consequences of specific behaviours by acknowledging the information. Second is the formation of habit; going through the process of routine actions being set and reinforced. The third function is the internalisation of behaviour. People become conscious as the consequences of their behaviour are confronted and adopt new attitudes to their new or changed behaviour. Particularly when using the feedback as a combined intervention with antecedent intervention like goal-setting, the effectiveness of such intervention achieves better results in bringing about change $[56,58,59]$. 
Matsumura and Fruchter [60] define feedback as a physical trigger that influences the behaviour change realised by a perceivable artefact, but add on an additional trigger of feedforward, which describes the "effect of perceived characteristics of availability, functionality and usability acquired from an artefact" [60] (p. 70). These types of strategies, based on assumption, focus on predicting information about the positive or negative consequences of intended behaviours in order to gain certain rewards from performing a new behaviour. As people respond to either antecedent interventions or positive incentives, when these strategies fail to achieve an anticipated result, often penalties can be enforced to limit unsustainable behaviours. Stern [24] points out that this consequential information (e.g., financial incentive) may influence behavioural change, but it is less likely to occur unless appropriate information makes individuals be aware that incentives are available. In other words, certain feedback (or forward) mechanism must be provided to inform the consequences of those new behaviours. As discussed above, behaviours influenced by feedback do not exist in a vacuum and must also be set in an organisational, social and cultural context.

Increasingly, calls have been made to embrace a more participatory approach to feedback in which the information provided cannot just be top-down or bottom-up, but feedforward. The notion of feedforward has been suggested as a potential role of design, whereby its representation goes beyond the function of feedback and provides an individual's selection of action that is based on future scenarios or predictions of the future state that can be speculative [61]; referred to as advice by [55]. The design element in this type of DfSB strategy may delegate more control for the inclusion of user's autonomously driven interaction in between services and product and increase its relationship to the user, which is created through voluntary occurrences. In the psychological domain, the concept of feedforward also has strict interconnection with motivation [62]. If user acceptance of the feedforward method is high and personalised, it could better inform and empower more responsible decision making via positive advisory information. In this context, it can be instructive to include feedforward strategy into the spectrum of the 'information' dimension, which could potentially instigate the internalisation of behavioural change in a more effective way.

\subsection{The Motivation}

A wide range of studies have been undertaken, with empirical evidence, that highlight the need to take into account different external variables, like incentive and penalty, to overcome behavioural change resistance $[24,40,63]$. Various DfSB strategies have been suggesting ways to stimulate both attitudinal and external factors affecting its behavioural determinant. This notion of encompassing both attitudinal (internal) and contextual (external) factors as determinants in bringing behaviour change originates from a psychological model called attitude-behaviour-context (ABC) [64] (See Figure 4). The model advocates concerns over studies using a single variable that results in the inconsistency of end results and an incomprehensive understanding of how behaviour change occurs. However, Jackson [45] explains the weakness of such an approach using an ABC model as an example of how behaviours are limited by external (contextual) factors; essentially there was no link between attitude and behaviour. Also, interventions addressing single factors are likely to be effective in the short-term, and that attitude may have a weak impact when behaviours are strongly regulated by external factors $[45,65]$. 


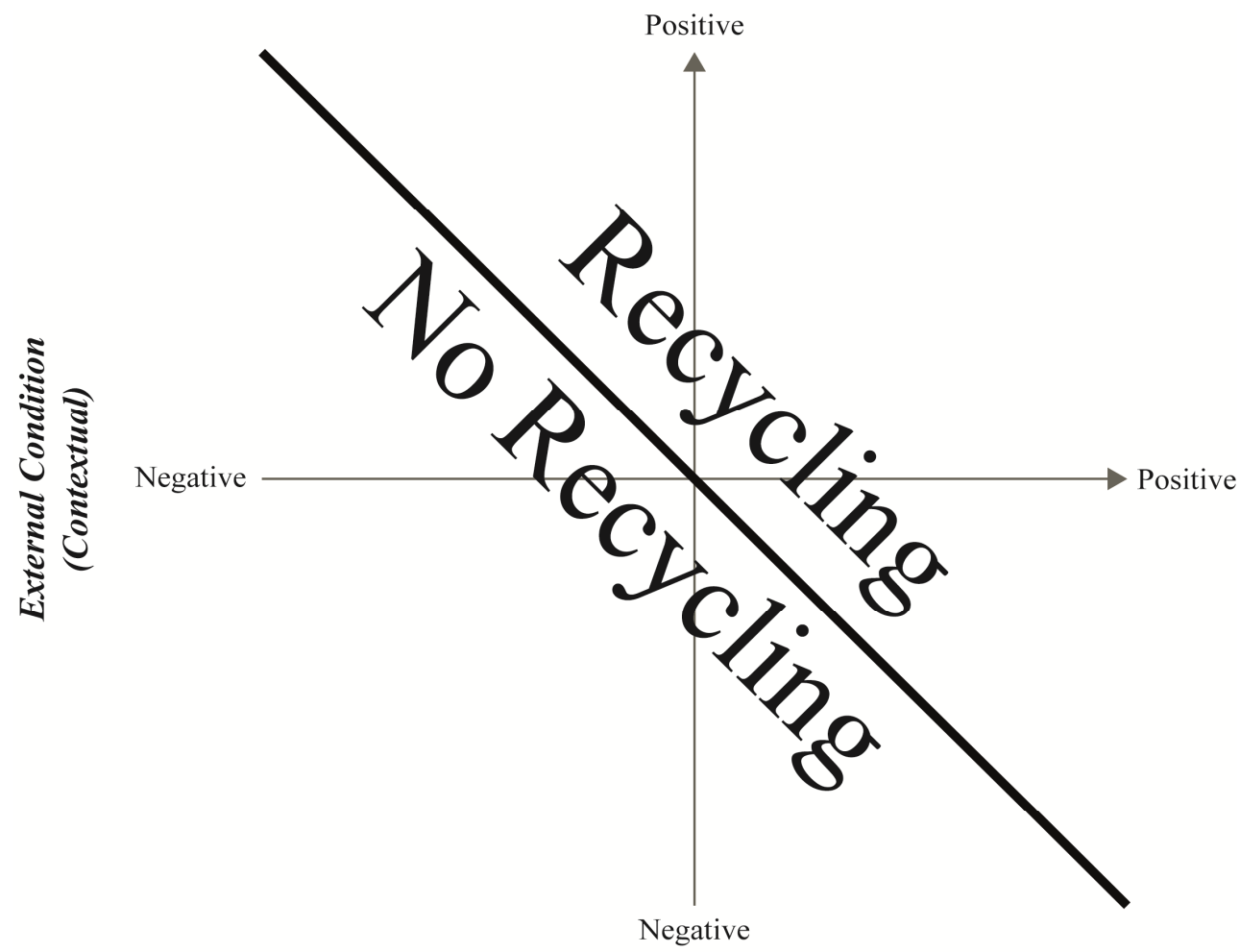

Attitude (A)

Figure 4. Attitude-belief-contextual (ABC) model of recycling [64].

While other academics emphasise the interventions dealing with feedback or the implications on external factors (extrinsic motivation such as incentive or penalty), De Young [42] highlights the importance of 'intrinsic motivation', which has an effect beyond tangible rewards like an incentive. He argues that 'intrinsic motivation' may reduce the side effects of intervention by making individuals discover a behaviour that is worth doing for its own right; inherent satisfaction gained by direct experience of those interventions. Deci and Ryan [66] argue that behaviours that are intrinsically motivated do not require reinforcements, since activities that are sufficiently interesting in themselves are intrinsically rewarding. Deci and Ryan [66] anticipated that intrinsically motivated behaviours are based on people's need to feel competent, self-determined, and autonomous; whereas people feel subsequently less motivated when they feel controlled by extrinsic motivation. However, they hypothesised that extrinsic motivations can be controlled invariably to the extent to which they are self-determined as they enact the regulation; known as self-determination theory (SDT). In support of this argument, they built the concept of 'internalisation', where behaviours affected by regulations are internalised through the processes of introjection, identification, or integration (see Figure 5). Extrinsic motivations can differ to the extent in which people are either controlled, sometimes punished or become autonomous through their feelings of the social norm. If a user of intervention has a lack of motivation for changing their behaviour, change can be instigated and controlled by either external regulations (potentially by others) or by introjected regulation that is carried out by an individual. Contrastingly, identified regulation can be generated by people having more ownership of their behaviour, thus becoming more autonomous. Finally, the 'internalisation' becomes most effective when the integrated regulation makes the individual perform self-determined behaviour that is in a fully volitional mode of action [66]. Therefore, they argue that non-intrinsically motivated behaviours can become truly self-determined. However, Deci and Ryan make clear a distinction between the intrinsic and fully 'internalised' extrinsic motivation by separating them with a vertical line; although they are volitional, the 'internalisation' is only possible through instrumentality, e.g., feeling responsible for performing sustainable behaviour. Presumably, the regulations within this internalisation process 
can be realised when the function of feedback (or forward) confronts user with the consequences of their actions.

\begin{tabular}{|c|c|c|c|c|c|c|}
\hline Behaviour & Nonself-determined & & & & & Self-determined \\
\hline Motivation & Amotivation & & Extrinsic & otivation & & Intrinsic Motivation \\
\hline $\begin{array}{l}\text { Regulatory } \\
\text { Styles }\end{array}$ & Non-Regulation & $\begin{array}{l}\text { External } \\
\text { Regulation }\end{array}$ & $\begin{array}{l}\text { Introjected } \\
\text { Regulation }\end{array}$ & $\begin{array}{l}\text { Identified } \\
\text { Regulation }\end{array}$ & $\begin{array}{l}\text { Integrated } \\
\text { Regulation }\end{array}$ & Intrinsic Regulation \\
\hline $\begin{array}{l}\text { Perceived } \\
\text { Locus of } \\
\text { Causality }\end{array}$ & Impersonal & Impersonal & $\begin{array}{l}\text { Somewhat } \\
\text { External }\end{array}$ & $\begin{array}{l}\text { Somewhat } \\
\text { Internal }\end{array}$ & Internal & Internal \\
\hline
\end{tabular}

Figure 5. Different types of motivation with their regulatory styles and the locus of causality [66].

So, once external factors create certain personal benefits, the intervention should focus on relating internal factors such as attitude and norm that eventually lead to activating new behaviours, rather than further increasing the external factor (e.g., incentives) [24], or vice versa. Darby [46] has also argued that there are downsides to these reinforcements of external factors where, once incentives are taken away, the changes are likely to fade away. This is, arguably, due to a lack of understanding of how those behaviours formulate within a regime of social practice and ignores complex issues like subjective experiences of interacting with feedback information. Thus, the effectiveness of combined interventions depends on how well the feedback information is explained and how the users interact with it. In other word, people are going through a learning process where information (feedback and/or forward) challenges their previous choices, and they adjust themselves to exercising a different choice in practice.

\section{Theoretical Implication of the Three Dimensions of DfSB}

Through a broad literature review encompassing DfSB, social science, behavioural studies and environmental psychology, the three dimensions of motivation, information and empowerment emerged. The framework (Figure 6) is an interpretive lens that can be used to view how these key dimensions are interrelated and are often interdependent of each other, to instigate a more efficient behaviour change leading to internalisation. Therefore, advancing the theoretical understanding of how these dimensions are interconnected becomes an important step for future studies of DfSB.

The framework argues that the internalisation of sustainable behaviours can be instigated by adopting the elements within these three dimensions when designing DfSB strategies. In aligning this approach, there is significant potential for internalised behaviour if strategies incorporate more empowerment to the user, allowing feedforward (including feedback) to help plan their future actions and facilitate more intrinsic motivation. However, it is important to note that the internalisation would require some degree of empirical process, which can be controlled and developed from behaviour induced by initial steps within the spectrum of dimensions, depending on the urgency of the behavioural problem. 
Sustainability 2019, 11, 4610

10 of 15

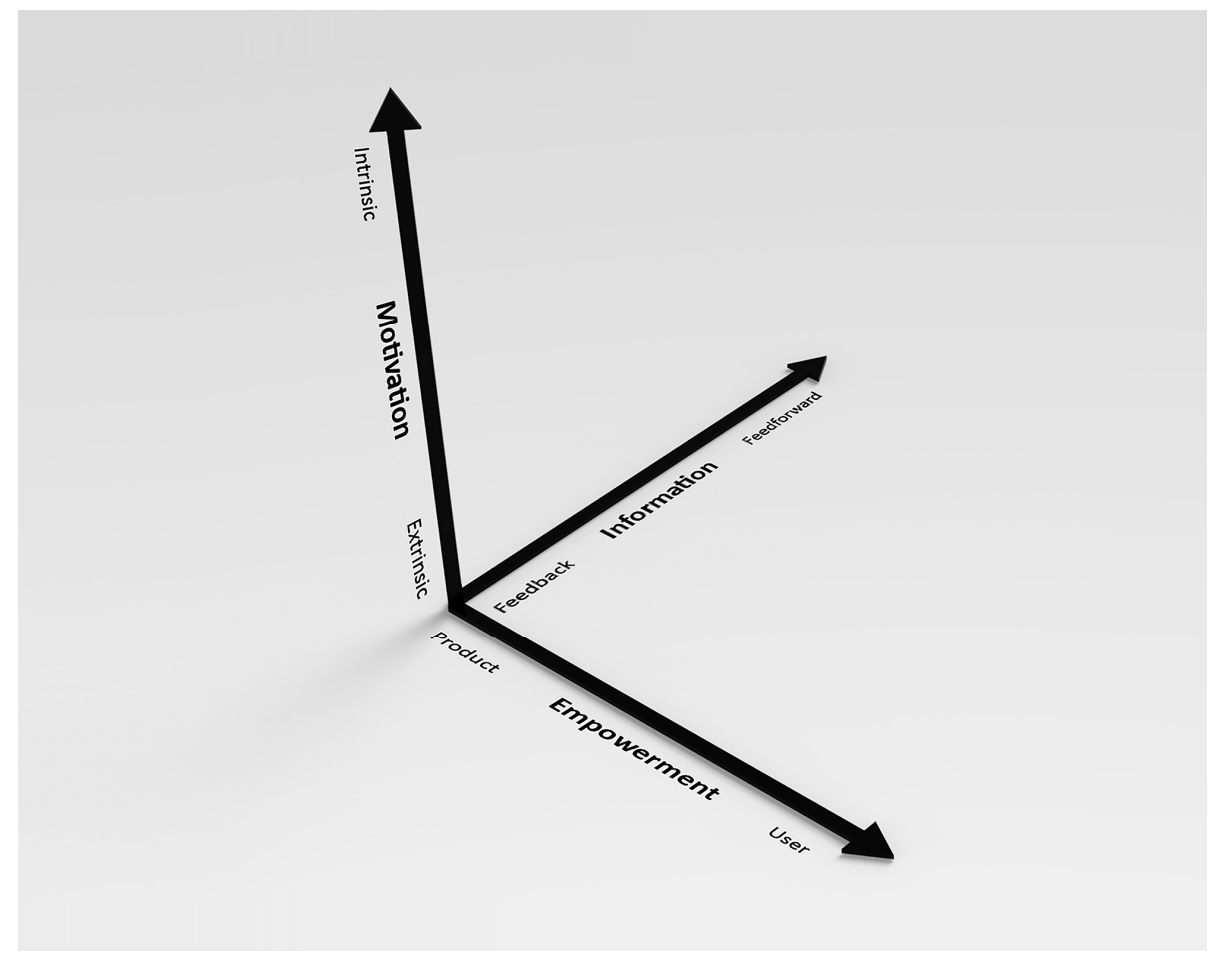

Figure 6. Three dimensions of DfSB strategies.

5. Practical Implication of the Three Dimensions of DfSB

The integration of three dimensions enables the framework to produce a typology of eight design spaces (see Figure 7), which would help the design and selection of DfSB strategies based on whether design attempts induce sustainable behaviour, prevent unsustainable behaviour or influence the habits of the target user.

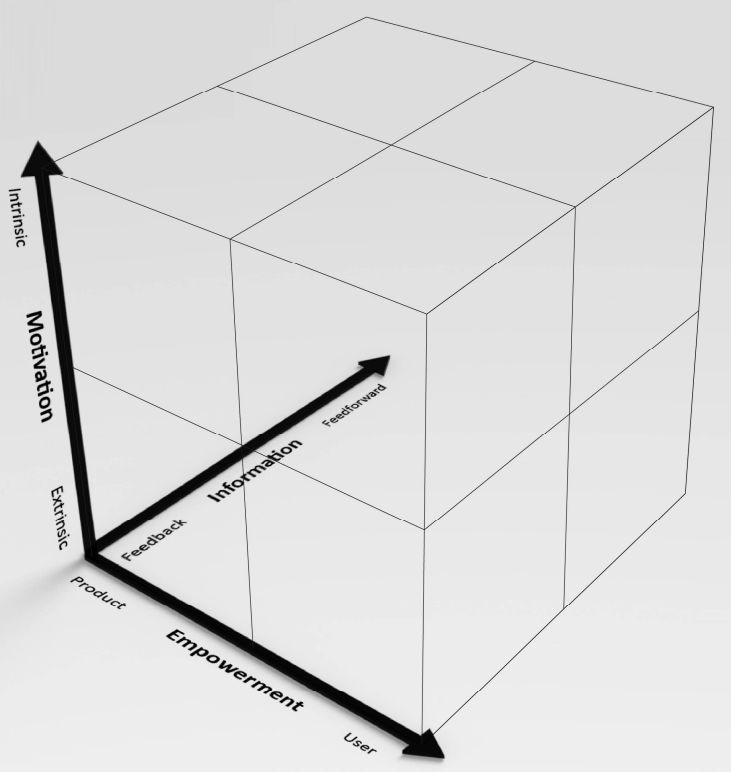

Figure 7. Typology of eight design spaces. 
Two practical examples illustrate this. Firstly, building on existing work linking human generated energy power to electricity consumption [11], the authors have an ongoing longitudinal study that investigates the effectiveness of the framework, focusing on instigating a daily exercise habit for people feeling physically inactive. The design-led intervention includes features relating to each dimension, providing empowerment via an exercise routine (or force exercise via constraining peripheral activity such as TV watching), feedback display indicating long and short-term consequences of changing behaviour (feedback and forward), and evaluation of the internalisation process through periodic qualitative interviews with the study participants; see [11] as an example. The internalised behaviour can be instigated through gradually delegating more empowerment of exercise to the user rather than by using force, causing the user to set daily exercise goals and make the behaviour itself be intrinsically rewarding (healthy).

The second example comes from within the field of architecture and the built environment. The authors have been involved in exploring participatory approaches in the design and implementation of energy feedback devices [67]. In this example, building users were positive about the benefits of engagement, and the design team were able to build a more bespoke and locally responsive application. Energy feedback tools can improve the visibility of energy consumption, and as a result of this engagement with building users the web-based responsive web application was able to begin to move beyond feedback and allow building users to share information with each other to try and understand the areas of wasteful consumption. Such tools then offer great potential, though it would be wrong to underestimate the challenging organisational, social and cultural contexts that these energy behaviours are situated within.

\section{Application and Reflections}

Given the scale of the environmental challenge before us, strategies of DfSB must be advanced to accommodate future facing behavioural interventions. The need for greater resource efficiency, reduced waste and the adoption of circular economy principles are vital if carbon reduction targets are to be met. Lessons need to be learnt, and frameworks and models from a broader range of disciplines than those previously considered need to be applied. This paper has presented a new framework, drawn from a wider literature base, to identify effective DfSB strategies and utilise them as a matrix to both further define categories and generate inclusive and open-ended discussion that can reveal new avenues to advance knowledge in this discipline.

For example, Ryan and Deci [68] emphasise the innate psychological needs in maintaining motivation, which is competence, autonomy and relatedness. All these needs have been lightly discussed in relation to the proposed framework. For instance, autonomy can be generated by having volitional control of behaviour (power in decision making) that is reinforced by intrinsic motivations; competence can be constructed by the utilisation of feedback mechanisms with varying motivations and relatedness can also be generated via external motivations and feedback systems (e.g., competition or online connection with others). However, Ryan and Deci [68] note that the feeling of competence will not enhance intrinsic motivation unless it is accompanied by a sense of autonomy.

Habitual behaviour, such as energy usage, is strongly embedded in inconspicuous norms of everyday practice. Whilst many case studies reported in the DfSB field focus on changing individual behaviour, recent scholars have emphasised the need for bringing a change at the practical level. It is important that future research combines and cross-references the fields of design discipline, social practice theory, environmental science and organisational studies, alongside environmental psychology, to greater understand behaviour within its wider context. This notion has profound implications for the potential impacts of interventions to influence sustainable behaviour by changing people's existing habits. Thus, strategies within DfSB should not merely depend upon influencing attitudes or using external factors but should instead change the practices. Further work is now required to apply this framework to refine and clarify the interdependent and interconnected dimensions. 


\section{Conclusions}

This paper has presented a new framework that proposes three dimensions to consider for DfSB studies. It has provided an explanatory concept for each dimension of empowerment, information, and motivation. The relationships and strategies associated with these dimensions are essentially an elaboration of the spectrums derived from previous studies, but further work has been carried out to recount how they are interconnected and interdependent to each other. It has discussed how these interdependent dimensions could make a constructive step towards modelling an internalisation of changed behaviour, serve as a guideline to formulate questions to further study, and provide a matrix to suggest new design spaces to accommodate development of more effective DfSB strategies. This will require future studies within DfSB to gain a better understanding of how cultural, social and material surroundings also have implications for sustainable behaviour, not simply focusing on behavioural problem such as energy consumption or carbon reduction but also wider strategies for sustainable development. We look forward to contributing to these debates.

Author Contributions: H.D.S. conceptualised the main contribution of the paper and drafted the initial manuscript, which was critically reviewed and edited by R.B., who made significant additions and contributions. All authors approved the final manuscript as submitted and agree to be accountable for all aspects of the work.

Funding: This research received no external funding.

Acknowledgments: We would like to thank the editors of the special issue and the reviewers of this paper. As can be seen from the references, this paper was much inspired by the work of many scholars in the field of Design for Sustainable Behaviour, so we appreciate their work so far in advancing the knowledge that lead to the construction of arguments made in this paper.

Conflicts of Interest: The authors declare no conflict of interest.

\section{References}

1. Raworth, K. Doughnut Economics: Seven Ways to Think Like A 21st-Century Economist; Chelsea Green Publishing: White River Junction, VT, USA, 2017.

2. WRAP. WRAP's Vision for the UK Circular Economy to 2020. Available online: http://www.wrap.org.uk/ content/wraps-vision-uk-circular-economy-2020 (accessed on 29 July 2019).

3. Bhamra, T.; Lofthouse, V. Design for Sustainability A Practical Approach; Gower: Aldershot, UK, 2007.

4. Bhamra, T.; Lilley, D. IJSE special issue: Design for Sustainable Behaviour. Int. J. Sustain. Eng. 2015, 8, 146-147. [CrossRef]

5. Lilley, D. Design for sustainable behaviour: Strategies and perceptions. Des. Stud. 2009, 30, 704-720. [CrossRef]

6. Elias, E. User-Efficient Design: Reducing the Environmental Impact of User Behaviour Through the Design of Products. Ph.D. Thesis, University of Bath, Bath, UK, 2011.

7. Lockton, D.; Harrison, D.; Stanton, N.A. The Design with Intent Method: A design tool for influencing user behaviour. Appl. Ergon. 2010, 41, 382-392. [CrossRef] [PubMed]

8. Wever, R.; van Kuijk, J.; Boks, C. User-centred design for sustainable behaviour. Int. J. Sustain. Eng. 2008, 1, 9-20. [CrossRef]

9. Wilson, G.T.; Lilley, D.; Bhamra, T. Design feedback interventions for household energy consumption reduction. In Proceedings of the 16th Conference of the European Roundtable on Sustainable Consumption and Production (ERSCP) \& the 7th Conference of the Environmental Management for Sustainable Universities (EMSU) (ERSCP-EMSU 2013), Istanbul, Turkey, 4-7 June 2013.

10. Tang, T.; Bhamra, T. Putting consumers first in design for sustainable behaviour: A case study of reducing environmental impacts of cold appliance use. Int. J. Sustain. Eng. 2012, 5, 288-303. [CrossRef]

11. Shin, H.D.; Bhamra, T. Design for sustainable behaviour: A case study of using human-power as an everyday energy source. J. Des. Res. 2016, 14, 280-299. [CrossRef]

12. Selvefors, A.; Pedersen, K.B.; Rahe, U. Design for sustainable consumption behaviour: Systematising the use of behavioural intervention strategies. In Proceedings of the 2011 Conference on Designing Pleasurable Products and Interfaces, Milan, Italy, 22-25 June 2011; p. 3. 
13. Boks, C. Design for Sustainable Behaviour Research Challenges. In Design for Innovative Value Towards A Sustainable Society; Matsumoto, M., Umeda, Y., Masui, K., Fukushige, S., Eds.; Springer: Dordrecht, The Netherlands, 2012; pp. 328-333. [CrossRef]

14. Strömberg, H.; Selvefors, A.; Renström, S. Mapping out the design opportunities: Pathways of sustainable behaviour. Int. J. Sustain. Eng. 2015, 8, 163-172. [CrossRef]

15. Daae, J.; Boks, C. A classification of user research methods for design for sustainable behaviour. J. Clean. Prod. 2014. [CrossRef]

16. Selvefors, A.; Renström, S.; Strömberg, H. Design for Sustainable Behaviour: A Toolbox for Targeting the Use Phase. In Proceedings of the Eco-design Tool Conference, Gothenburg, Sweden, 14-15 May 2014.

17. Kuijer, L.; Bakker, C. Of chalk and cheese: Behaviour change and practice theory in sustainable design. Int. J. Sustain. Eng. 2015, 8, 219-230. [CrossRef]

18. Lilley, D.; Wilson, G.T. Intergrating Ethics into design for sustainable behaviour. J. Des. Res. 2013, 11, $278-299$.

19. Zachrisson, J.; Boks, C. Exploring behavioural psychology to support design for sustainable behaviour research. J. Des. Res. 2012, 10, 50-66. [CrossRef]

20. Wilson, G.T.; Bhamra, T.; Lilley, D. The considerations and limitations of feedback as a strategy for behaviour change. Int. J. Sustain. Eng. 2015, 1-10. [CrossRef]

21. Coskun, A.; Zimmerman, J.; Erbug, C. Promoting sustainability through behavior change: A review. Des. Stud. 2015, 41, 183-204. [CrossRef]

22. De Medeiros, J.F.; Da Rocha, C.G.; Ribeiro, J.L.D. Design for sustainable behavior (DfSB): Analysis of existing frameworks of behavior change strategies, experts' assessment and proposal for a decision support diagram. J. Clean. Prod. 2018, 188, 402-415. [CrossRef]

23. Zachrisson, J.; Boks, C. Dimensions of behaviour change. J. Des. Res. 2014, 12, 145-172. [CrossRef]

24. Stern, P.C. Information, incentives, and proenvironmental consumer behavior. J. Consum. Policy 1999, 22, 461-478. [CrossRef]

25. Jelsma, J.; Knot, M. Designing environmentally efficient services; a 'script' approach. J. Sustain. Prod. Des. 2002, 2, 119-130. [CrossRef]

26. Norman, D.A. Affordance, conventions, and design. Interactions 1999, 6, 38-43. [CrossRef]

27. Lilley, D.; Lofthouse, V.A.; Bhamra, T.A. Towards instinctive sustainable product use. In Proceedings of the 2nd International Conference in Sustainability, Creating the Culture, Aberdeen, UK, 2-4 November 2005.

28. Bhamra, T.; Lilley, D.; Tang, T. Design for Sustainable Behaviour: Using Products to Change Consumer Behaviour. Des. J. 2011, 14, 427-445. [CrossRef]

29. Lilley, D.; Wilson, G.; Bhamra, T.; Hanratty, M.; Tang, T. Design interventions for sustainable behaviour. In Design for Behaviour Change: Theories and Practices of Designing for Change; Routledge: Abingdon-on-Thames, UK, 2017.

30. Zachrisson, J.; Storrø, G.; Boks, C. Using a guide to select design strategies for behaviour change; Theory vs. Practice. In Design for Innovative Value Towards a Sustainable Society; Matsumoto, M., Umeda, Y., Masui, K., Fukushige, S., Eds.; Springer: Dordrecht, The Netherlands, 2012; pp. 362-367. [CrossRef]

31. Gardner, G.T.; Stern, P.C. The short list: The most effective actions US households can take to curb climate change. Environ. Sci. Policy Sustain. Dev. 2008, 50, 12-25. [CrossRef]

32. Latour, B. Where Are the Missing Masses? The Sociology of a Few Mundane Artifacts. In Shaping Technology/Building Society: Studies in Sociotechnical Change; Bijker, W.E., Law, J., Eds.; MIT Press: Cambridge, MA, USA, 1992; pp. 225-258.

33. Jelsma, J. Philosophy meets Design, or how the masses are missed (and revealed again) in environmental policy and ecodesign. In Consumption, Everyday Life and Sustainability, Reader for ESF Summer School 1999, Lancaster University; Cetre for Science Studies: Lancaster, UK, 1999.

34. Ingram, J.; Shove, E.; Watson, M. Products and Practices: Selected Concepts from Science and Technology Studies and from Social Theories of Consumption and Practice1. Des. Issues 2007, 23, 3-16. [CrossRef]

35. Jelsma, J. Designing 'moralized'products. In User Behavior and Technology Development; Springer: Dordrecht, 2006; pp. 221-231.

36. Brey, P. Ethical aspects of behavior-steering technology. In User Behavior and Technology Development; Springer: Dordrecht, The Netherlands, 2006; pp. 357-364.

37. Brey, P. The strategic role of technology in a good society. Technol. Soc. 2018, 52, 39-45. [CrossRef] 
38. Tang, T. Towards Sustainable use: Design Behaviour Intervention to Reduce Household Environment Impact. Ph.D. Thesis, Loughborough University, Loughborough, UK, 2010.

39. Geller, E.S.; Berry, T.D.; Ludwig, T.D.; Evans, R.E.; Gilmore, M.R.; Clarke, S.W. A conceptual framework for developing and evaluating behavior change interventions for injury control. Health Educ. Res. 1990, 5, 125-137. [CrossRef]

40. Verplanken, B.; Wood, W. Interventions to Break and Create Consumer Habits. J. Public Policy Mark. 2006, 25, 90-103. [CrossRef]

41. Steg, L.; Vlek, C. Encouraging pro-environmental behaviour: An integrative review and research agenda. J. Environ. Psychol. 2009, 29, 309-317. [CrossRef]

42. De Young, R. Changing behavior and making it stick The conceptualization and management of conservation behavior. Environ. Behav. 1993, 25, 485-505. [CrossRef]

43. Arnstein, S.R. A Ladder Of Citizen Participation. J. Am. Inst. Plan. 1969, 35, 216-224. [CrossRef]

44. Bull, R.; Janda, K.B. Beyond feedback: Introducing the 'engagement gap'in organizational energy management. Build. Res. Inf. 2018, 46, 300-315. [CrossRef]

45. Jackson, T. Motivating Sustainable Consumption: A Review of Evidence on Consumer Behaviour and Behavioural Change: A Report to the Sustainable Development Research Network/Tim Jackson; Centre for Environmental Strategy: Guildford, UK, 2005.

46. Darby, S. The Effectiveness of Feedback on Energy Consumption: A Review for DEFRA of the Literature on Metering, Billing and Direct Displays; Environmental Change Institute, University of Oxford: Oxford, UK, 2006.

47. Fischer, C. Feedback on household electricity consumption: A tool for saving energy? Energy Effic. 2008, 1, 79-104. [CrossRef]

48. Pierce, J.; Fan, C.; Lomas, D.; Marcu, G.; Paulos, E. Some consideration on the (in) effectiveness of residential energy feedback systems. In Proceedings of the 8th ACM Conference on Designing Interactive Systems, Aarhus, Denmark, 16-20 August 2010; pp. 244-247.

49. Fitzpatrick, G.; Smith, G. Technology-enabled feedback on domestic energy consumption: Articulating a set of design concerns. IEEE Pervasive Comput. 2009, 8, 37-44. [CrossRef]

50. Burgess, J.; Nye, M. Re-materialising energy use through transparent monitoring systems. Energy Policy 2008, 36, 4454-4459. [CrossRef]

51. Strengers, Y.A.A. Designing eco-feedback systems for everyday life. In Proceedings of the 2011 Annual Conference on Human Factors in Computing Systems, Vancouver, BC, Canada, 7-12 May 2011; pp. 2135-2144.

52. Hargreaves, T.; Nye, M.; Burgess, J. Making energy visible: A qualitative field study of how householders interact with feedback from smart energy monitors. Energy Policy 2010, 38, 6111-6119. [CrossRef]

53. Bandura, A. Self-efficacy: toward a unifying theory of behavioral change. Psychological review 1977, 84, 191. [CrossRef]

54. Hargreaves, T.; Nye, M.; Burgess, J. Keeping energy visible? Exploring how householders interact with feedback from smart energy monitors in the longer term. Energy Policy 2013, 52, 126-134. [CrossRef]

55. Yun, R.J.; Aziz, A.; Lasternas, B. Design implications for the presentation of eco-feedback data. Arch. Des. Res. 2015, 28, 95-106. [CrossRef]

56. Abrahamse, W.; Steg, L.; Vlek, C.; Rothengatter, T. A review of intervention studies aimed at household energy conservation. J. Environ. Psychol. 2005, 25, 273-291. [CrossRef]

57. Backlund, S.; Gyllenswärd, M.; Gustafsson, A.; Ilstedt Hjelm, S.; Mazé, R.; Redström, J. STATIC! The Aesthetics of Energy in Everyday Things. In Proceedings of the 2006 Design Research Society Wonderground International Conference, Lisbon, Portugal, 1-4 November 2006.

58. Van Houwelingen, J.H.; van Raaij, W.F. The effect of goal-setting and daily electronic feedback on in-home energy use. J. Consum. Res. 1989, 16, 98-105. [CrossRef]

59. McCalley, L. From motivation and cognition theories to everyday applications and back again: The case of product-integrated information and feedback. Energy Policy 2006, 34, 129-137. [CrossRef]

60. Matsumura, N.; Fruchter, R. Shikake trigger categories. In Proceedings of the 2013 AAAI Spring Symposium Series, Stanford, CA, USA, 25-27 March 2013.

61. Lockton, D.; Harrison, D.; Stanton, N. Design with Intent: 101 Patterns for Influencing Behaviour through Design; Equifine: Middlesex, UK, 2010.

62. Basso, D.; Belardinelli, M.O. The role of the feedforward paradigm in cognitive psychology. Cogn. Process. 2006, 7, 73-88. [CrossRef] 
63. Pierce, J.; Schiano, D.J.; Paulos, E. Home, habits, and energy: Examining domestic interactions and energy consumption. In Proceedings of the 28th International Conference on Human Factors in Computing Systems, CHI 2010, Atlanta, GA, USA, 10-15 April 2010; pp. 1985-1994.

64. Stern, P.C. New environmental theories: Toward a coherent theory of environmentally significant behavior. J. Soc. Issues 2000, 56, 407-424. [CrossRef]

65. Wilson, C.; Dowlatabadi, H. Models of decision making and residential energy use. Annu. Rev. Environ. Resour. 2007, 32, 169-203. [CrossRef]

66. Deci, E.L.; Ryan, R.M. The "What" and "Why" of Goal Pursuits: Human Needs and the Self-Determination of Behavior. Psychol. Inq. 2000, 11, 227-268. [CrossRef]

67. Bull, R.; Lemon, M.; Everitt, D.; Stuart, G. Moving beyond feedback: Energy behaviour and local engagement in the United Kingdom. Energy Res. Soc. Sci. 2015, 8, 32-40. [CrossRef]

68. Ryan, R.M.; Deci, E.L. Self-Determination Theory and the Facilitation of Intrinsic Motivation, Social Development, and Well-Being. Am. Psychol. 2000, 55, 68-78. [CrossRef]

(C) 2019 by the authors. Licensee MDPI, Basel, Switzerland. This article is an open access article distributed under the terms and conditions of the Creative Commons Attribution (CC BY) license (http://creativecommons.org/licenses/by/4.0/). 